\title{
Antioxidative effects of proteoglycans of embryonic genesis in streptozotocin-induced diabetic rats
}

\author{
This article was published in the following Dove Press journal: \\ Research and Reports in Biochemistry \\ 24 January 2013 \\ Number of times this article has been viewed
}

\author{
Vahid Vahedian' \\ Yelena M Aghajanova ${ }^{2}$ \\ Gevorg A Kevorkian ${ }^{3}$ \\ Maxim A Simonyan ${ }^{3}$ \\ 'Department of Biochemistry, \\ ${ }^{2}$ Department of Endocrinology, \\ Yerevan State Medical University \\ after M Heratsi, Yerevan, Armenia, \\ ${ }^{3}$ Buniatyan Institute of Biochemistry, \\ National Academy of Science, Yerevan, \\ Armenia
}

Introduction: It is well accepted that oxidative stress plays a significant role in the pathogenesis of diabetes mellitus. The objective of this study was to investigate the effect of proteoglycans of embryonic genesis (PEG) on concentrations and activity of prooxidative and antioxidative metalloproteins in streptozotocin (STZ)-induced diabetes in rats.

Methods: Study groups were as follows: vehicle control group (Group 1), STZ-induced diabetes $(55 \mathrm{mg} / \mathrm{kg}$, intraperitoneal injection [Group 2]), STZ-induced diabetes with prophylactic injection of PEG $(0.5 \mathrm{mg} / \mathrm{kg}$ intraperitonealy injected $) 1$ week prior to STZ injection (Group 3). The following prooxidative metalloproteins were studied: levels of nicotinamide adenine dinucleotide phosphate (NADPH) oxidase (Nox) isoforms (extracellular Nox [eNox]) in serum; erythrocyte membranes; and spleen cell membranes, nucleus and mitochondria, as well as serum levels of superoxide-producing lipoprotein (suprol); cytochrome (cyt) $b_{5}$ from cytosol of erythrocytes; and cyt $\mathrm{c}$ from spleen cell cytosol. The antioxidative metalloproteins, particularly superoxide dismutase and catalase from erythrocyte and from spleen cell cytosol were studied.

Results: Results demonstrated the significant $(P<0.05)$ increase in the level and activity of NADPH-dependent, $\mathrm{O}_{2}^{-}$-producing eNox activity in Group 2 in comparison with the control Group and decrease of the ferrihemoglobin-reducing activities of these Nox, as well as a significant increase in $\mathrm{O}_{2}{ }^{-}$-producing activity of suprol. In Group 2, there was a significant elevation of the level of cyt $c$, and decreased cyt $b_{5}$ level, as well as inhibition of superoxide dismutase and catalase activity.

Conclusion: The prophylactic injection of the PEG demonstrated overall antioxidative effect, with prevention of changes in prooxidative markers.

Keywords: proteoglycans of embryonal genesis (PEG), streptozotocin-induced diabetes, antioxidant, prevention

\section{Introduction}

Mechanisms of pathological change in streptozotocin (STZ)-induced diabetes is conditioned by various factors. The STZ penetrating into the beta-cells of a pancreas along with glucose causes alkylation of DNA, impairment of which induces activation of the poly-adenosine diphosphate-ribosylation process with depletion of cellular NAD ${ }^{+}$ and ATP. Increased dephosphorylation of adenosine triphosphate under the influence of STZ leads to the formation of a substrate for xanthine-xanthine oxidase and of $\mathrm{O}_{2}^{-}$, $\mathrm{H}_{2} \mathrm{O}_{2}$, and $\mathrm{HO}$, resulting in denaturation of beta-cells that causes apoptosis. ${ }^{1} \mathrm{STZ}$ suppresses the oxidation of glucose ${ }^{2}$ and the biosynthesis and secretion of insulin, ${ }^{3}$ serving as an NO donor, which also damages the beta-cells and DNA. ${ }^{4}$
Correspondence: Vahid Vahedian Department of Biochemistry, Yerevan State Medical University after M Heratsi, 2 Koryun Street 0025, Yerevan, Armenia Tel +37477 792 I64;

+37410565326

Email vahedian.vahid@gmail.com 
In STZ-induced diabetes, the increase of the level of reactive oxygen species (ROS), due to the elevation of the levels of isoforms of nicotinamide adenine dinucleotide phosphate (NADPH oxidase (Nox), causes nephropathy and oxidative stress of renal cells, ${ }^{5,6}$ as well as endothelial dysfunction of pulmonary arteries. ${ }^{7}$ This, in turn, leads to a significant decrease of the antioxidant status of the organism. ${ }^{8,9}$ A decrease of the activity of Nox by apocynin (the inhibitor of the Nox) plays a positive role in mice with STZ- induced diabetes by elevating insulin levels and decreasing the degree of destruction of beta-cells in the pancreas. ${ }^{10}$ Medications with antioxidant activity (SOD-mimetic complexes, such as D-pinitol from soybean oil and Punica granatum flowers) also have regulatory action in STZ- induced diabetes. ${ }^{11-13}$

The specified exogenous protective factors regulate not only the metabolism of ROS, but also the immune system, operation of which is closely connected to this metabolism. ${ }^{14}$ From this perspective, proteoglycans of embryonal genesis (PEG), also known as the embryonic anti-tumor modulator of Mkrtchyan, ${ }^{15}$ which effectively stimulate the organism's immune system ${ }^{16,17}$ and have been shown to have a neuroprotective action, ${ }^{18}$ may also be effective in STZ-induced diabetes, providing an anti-stressor effect.

The aims of this study were: (1) to determine the level of NADPH-dependent, $\mathrm{O}_{2}{ }^{-}$-producing ${ }^{19}$ and ferrihemoglobin (ferriHb)-reducing activity ${ }^{20}$ of Nox from erythrocyte membranes (EM), from serum, and from spleen cell membranes (SCM), nuclei (SCN) and mitochondria (SCMI); (2) to determine the level and $\mathrm{O}_{2}{ }^{-}$-producing activity of superoxide-producing lipoprotein (suprol); (3) to determine the levels of cytochrome (cyt) c and cyt $b_{5}$; (4) to determine the activity of key antioxidant enzymes-metalloproteins $\mathrm{Cu}$, Zn-superoxide dismutase (SOD), Mn-SOD, and catalase; ${ }^{21-23}$ and (5) to determine the possible protective role of PEG if administered in a prophylactic (preventive) regimen in rats with STZ-induced diabetes.

\section{Materials and methods}

The experiments were carried out on white wild-type male rats weighing 200-220 g, with 12 rats in each group. Control group animals (Group 1) were injected with a one-time intraperitoneal (ip) $0.5 \mathrm{~mL}$ water as vehicle. Diabetes was induced in Group 2 animals with a one-time ip injection of STZ (Sigma-Aldrich, St Louis, MO) at a dose of $55 \mathrm{mg} / \mathrm{kg}$ body weight. In Group 3, animals received an ip injection of PEG (0.5 mg/kg body mass), and 7 days later received an ip injection of STZ (55 mg/kg) (prophylactic regimen). PEG (the embryonic anti-tumor modulator) was kindly provided by Professor LN Mkrtchyan. The rats were decapitated under phenobarbital anesthesia (40 mg/kg) after 21 days. Blood was stabilized by $0.2 \%$ sodium oxalate.

\section{Isolation of fractions of the Nox isoforms from the cell components of the spleen}

The fractions of the Nox isoforms from SCN, SCMI, and SCM were obtained as described earlier without use of detergent for solubilization of these hemoproteins. ${ }^{24}$ After washing the spleen tissue (up to $4 \mathrm{~g}$ ) with physiologic solution, homogenization in $0.25 \mathrm{M}$ sucrose $(1 \mathrm{~g}$ tissue in $10 \mathrm{~mL}$ sucrose) in a glass homogenizer with teflon pestle for 1 minute at $4^{\circ} \mathrm{C}$ was conducted.

SCN, SCM, and SCMI were precipitated by differential centrifugation. Sediments were washed twice with sucrose solution (1:20) then centrifuged (10,000 g, 10 minutes). For further precipitation, nuclei, mitochondria, and cell membranes were washed with water (1:50) and again centrifuged $(10,000 \mathrm{~g}, 10$ minutes). Purified from traces of sucrose and other impurities, water-soluble precipitates of SCN, SCM, and SCMI were mixed with water (1:5) and finally homogenized in an analogous manner. After solubilization of the protein fractions ${ }^{23}$ and centrifugation of these mixtures, the supernatants were separately subjected to ion-exchange chromatography on the column of cellulose CM-52, equilibrated by $0.004 \mathrm{M}$ potassium phosphate buffer (PPB) $\mathrm{pH} 7.4$ to remove traces of hemoglobin or other associated proteins of the basic character. Protein fractions not detained on a column with CM-52 were subjected to ion-exchange chromatography on the column of DE-52 cellulose, and the Nox from SCN, SCM, and SCMB were eluted using $0.2 \mathrm{M}$ PPB.

\section{Isolation of Nox from EM}

The Nox from EM were isolated by the same solubilization method, centrifugation $(14,000 \mathrm{~g}, 15$ minutes $)$ and ion-exchange chromatography of the supernatant on celluloses CM-52 and DE-52, from which the Nox was eluted using $0.4 \mathrm{M} \mathrm{PPB} .^{20}$

\section{Isolation of suprol and Nox from blood serum}

After incubation of the blood serum (for 4 days at $4^{\circ} \mathrm{C}$ ) and purification from traces of erythrocytes and plasma cells, the serum was dialyzed against water. After precipitation and activation of suprol with $0.05 \mathrm{M} \mathrm{FeCI}_{3}$ for the production of $\mathrm{O}_{2}^{-}$, suprol precipitate was isolated by centrifugation at $6000 \mathrm{~g}$ for 10 minutes. ${ }^{22}$ The fraction of Nox was isolated from 
the supernatant, after its ion-exchange chromatography on the Sephadex DEAE A-50 (Pharmacia, Stockholm, Sweden) (the Nox eluted with 0.04 M PPB). After 20-fold dilution of this eluate with water and ion-exchange chromatography on a column of cellulose DE-52, the fraction of Nox from blood serum (extracellular Nox or eNox) was also eluted with $0.04 \mathrm{M}$ PPB.

The concentration of the Nox isoforms was determined by measuring the optical absorption density at $\mathrm{A}_{530} \mathrm{~nm}$ (beta absorption band) characteristic for the Nox. Specific content was determined for the Nox isolated from $1 \mathrm{~g}$ of spleen, $1 \mathrm{~mL}$ of serum, and $1 \mathrm{~mL}$ of erythrocytes.

\section{Determination of NADPH dependent $\mathrm{O}_{2}^{-}$-producing activity of Nox isoforms} NADPH-dependent $\mathrm{O}_{2}{ }^{-}$-producing activity of Nox isoforms was determined by nitrotetrazolium blue (NTB) method at $560 \mathrm{~nm}$, the percentage of formazan formed was calculated as a result of the reduction of NTB by superoxide radicals. ${ }^{19}$ The unit of NADPH-dependent, $\mathrm{O}_{2}^{-}-$ producing activity of Nox was considered the amount of mg of the enzyme protein, which stimulates the formation of formazan by $50 \%$.

\section{Determination of ferriHB-reducing activity of Nox isoforms}

FerriHb-reducing activity of the Nox isoforms was determined using the freshly obtained ferriHb from rat erythrocyte cytoplasm by measuring the optical absorption density (alpha absorption band) at $565 \mathrm{~nm}=0.8$ optical units. Directly in quartz cuvettes of spectrophotometer, the $0.2 \mathrm{~mL}$ of Nox with $\mathrm{A}_{530}=0.3$ optical units was added to $3 \mathrm{~mL}$ of ferriHb solution. After stirring, the reaction mixture was incubated under aerobic conditions for 15-16 hours at $30^{\circ} \mathrm{C}$. Further, after remixing the reaction mixture, the kinetics of reduction of ferriHb to ferroHb by measuring the decrease of the absorption density of ferriHb at $565 \mathrm{~nm}$ was determined (this decrease is in direct proportion to the formed ferroHb measured at $555 \mathrm{~nm}$ ). The amount of protein causing a decrease of the optical absorption density of ferriHb up to 0.05 during 1 hour at $20^{\circ}$ was considered the unit of ferriHb-restoring activity of Nox.

\section{Isolation of the fractions of SOD, catalases, and cyt $b_{5}$ from cytosol of erythrocytes, and determination of SOD and catalase activity}

After washing out self-precipitated erythrocytes with normal saline $(1: 100 \mathrm{vol} / \mathrm{vol})$ from traces of plasma cells and hemolysis with water $(1: 10 \mathrm{vol} / \mathrm{vol})$, the EM were precipitated by centrifugation of hemolysate at $\mathrm{pH} 5.6$ (6000 g, 15 minutes); thereafter the supernatant solution was dialyzed against water and, after centrifugation, the supernatant was subjected to ion-exchange column chromatography with cellulose DE-52 (equilibrated with the $0.002 \mathrm{M}$ PPB). The total fraction of $\mathrm{Cu}, \mathrm{Zn}-\mathrm{SOD}$, and catalase was eluted with $0.04 \mathrm{M} \mathrm{PPB}$, and cyt $\mathrm{b}_{5}$ was eluted with $0.2 \mathrm{M}$ PPB. The amount of cyt $b_{5}$ was determined by measuring the optical absorption density at $525 \mathrm{~nm}$ (beta absorption band).

The SOD activity was determined by NTB method measuring the optical absorption density of formazan (at $560 \mathrm{~nm}$ ). The unit of SOD activity was considered the amount of $\mathrm{mg}$ of the enzyme protein causing $50 \%$ decrease of optical absorption density of formazan.

The catalase activity was determined by permanganometric titration of hydrogen peroxide solution in the absence or presence of catalase. One unit of catalase activity was defined to be the amount of protein that caused splitting of $0.1 \mathrm{M}$ hydrogen peroxide in 1 minute at $20^{\circ} .{ }^{24}$

Table I The change of the specific levels (specific optical absorption density) of MPA in study groups

\begin{tabular}{|c|c|c|c|}
\hline \multirow[t]{2}{*}{$\overline{M P A}$} & \multicolumn{3}{|c|}{ Units of optical density } \\
\hline & Group I & Group 2 & Group 3 \\
\hline Extracellular Nox from blood serum & $0.15 \pm 0.02$ & $0.28 \pm 0.03, P=0.01$ & $0.25 \pm 0.02, P=0.04$ \\
\hline Nox from EM & $0.45 \pm 0.07$ & $0.97 \pm 0.09, P=0.02$ & $0.73 \pm 0.06, P=0.02$ \\
\hline Nox from SCM & $1.20 \pm 0.1$ & $2.17 \pm 0.04, P=0.01$ & $1.76 \pm 0.08, P=0.01$ \\
\hline Nox from SCN & $0.70 \pm 0.05$ & $2.25 \pm 0.10, P=0.031$ & $0.96 \pm 0.04, P=0.02$ \\
\hline Nox from SCMI & $0.18 \pm 0.02$ & $0.46 \pm 0.03, P=0.01$ & $0.36 \pm 0.03, P=0.01$ \\
\hline cyt $b_{5}$ from cytosol of erythrocytes & $0.09 \pm 0.01$ & $0.054 \pm 0.003, P=0.02$ & $0.053 \pm 0.003, P=0.04$ \\
\hline cyt c from cytosol of spleen cells & $0.08 \pm 0.006$ & $0.14 \pm 0.02, P=0.04$ & $0.10 \pm 0.02, P=0.01$ \\
\hline
\end{tabular}

Notes: Data are expressed as mean \pm SD. Significance accepted at $P<0.05 ; \mathrm{n}=16$ in each group.

Abbreviations: MPA, prooxidative metalloproteins; EM, erythrocyte membrane; SCM, spleen cell membrane; SCN, spleen cell nuclei; SCMI, spleen cell mitochondria; cyt, cytochrome. 
Table 2 NADPH-dependent, $\mathrm{O}_{2}^{-}$-producing activity of Nox and suprol in study groups

\begin{tabular}{llll}
\hline MPA & \multicolumn{2}{l}{ Units of optical density/mg protein } & Group 3 \\
\cline { 2 - 4 } & Group I & Group 2 & $32.9 \pm 3.0, P=0.03$ \\
\hline Extracellular Nox from blood serum & $25.1 \pm 2.3$ & $36.4 \pm 4.1, P=0.04$ & $19.8 \pm 2.7, P=0.03$ \\
Nox from EM (suprol) & $12.9 \pm 1.6$ & $27.1 \pm 5.0, P=0.04$ & $36.4 \pm 7.0, P=0.03$ \\
Nox from SCM & $14.1 \pm 1.5$ & $47.7 \pm 6.1, P=0.01$ & $19.1 \pm 2.0, P=0.04$ \\
Nox from SCN & $12.2 \pm 1.4$ & $21.8 \pm 3.1, P=0.03$ & $16.8 \pm 2.3, P=0.01$ \\
Nox from SCMI & $12.1 \pm 0.7$ & $20.7 \pm 2.8, P=0.01$ &
\end{tabular}

Notes: Data are expressed as mean \pm SD. Significance accepted at $P<0.05 ; \mathrm{n}=16$ in each group.

Abbreviations: NADPH, nicotinamide adenine dinucleotide phosphate; suprol, superoxide-producing lipoprotein; MPA, prooxidative metalloproteins; EM, erythrocyte membrane; SCM, spleen cell membrane; SCN, spleen cell nuclei; SCMI, spleen cell mitochondria.

Isolation of the total fraction of $\mathrm{Cu}$, Zn-SOD, Mn-SOD, catalase, and cyt c from the cytosol of spleen cells

Spleen cell cytosols were dialyzed against water and centrifuged, and the supernatant subjected to ion-exchange chromatography on the column with cellulose CM-52, from which cyt c was eluted with $0.2 \mathrm{M}$ PPB. ${ }^{23}$ Fractions of SOD and catalase do not absorb on this column, but are deposited on a column with cellulose DE-52, from which the total fraction of SOD and catalase was eluted with $0.04 \mathrm{M}$ PPB. The SOD and catalase activities were determined by the method described above, and the specific activity was estimated for $1 \mathrm{~g}$ of spleen.

All optical spectral measurements were carried out on a SPECORD ${ }^{\circledR}$ UV/VIS spectrophotometer (Analytik Jena AG, Jena, Germany) in a $1 \mathrm{~cm}$ cuvette. The statistical processing of the results was carried out by Student's $t$ - and Fisher's exact tests by definition of reliability criterion $P$. A $P$-value of $\leq 0.05$ was considered significant.

\section{Results}

Changes in the level of metalloproteins of prooxidant activity (isoforms of Nox, localized in the blood serum, EM, SCN, SCM, and SCMI, as well as cyt c, cyt $b_{5}$, and suprol) and metalloproteins of antioxidant activity $(\mathrm{Cu}, \mathrm{Zn}-$
SOD and catalase from erythrocyte and cytosol and the total fraction of $\mathrm{Cu}, \mathrm{Zn}$-SOD, Mn-SOD, and catalase from spleen cell cytosol) were observed as described below and in Tables 1-4.

In STZ-induced diabetes (Group 2), the level of Noxes was significantly increased (from $81.5 \%$ to $225 \%$ ) in EM, SCM, SCN, and SCMI. The level of cyt c was significantly increased in spleen cells, indicating the decrease of the stability of mitochondria in the STZ-induced diabetes, although the level of cyt $b_{5}$ from the cytosol of erythrocytes was decreased (Table 1).

In Group 3, under the influence of prophylactically injected PEG, Nox in the EM, SCM, SCN, and SCMI were mainly saved near to the normal values (Table 1).

As shown in Table 2, the $\mathrm{O}^{2}$-producing activity of suprol and Nox, isolated from blood serum, EM, SCN, SCM, and SCMI of rats with experimental diabetes, increased sharply. ${ }^{30}$

The PEG had a protective effect, retaining the $\mathrm{O}_{2}^{-}$-producing activity of isoforms of the Noxes and suprol near to the norm.

FerriHb-reducing activity of all Nox studied was considerably decreased in STZ-induced diabetes, especially for the Nox from EM and eNox (Table 3), indicating a significant disruption of oxygen homeostasis. In this case, PEG basically prevents the change of the oxygen homeostasis.

Table 3 The specific ferriHb-reducing activity of Nox in study groups

\begin{tabular}{lccr}
\hline MPA & \multicolumn{3}{c}{ Units of optical density/mg protein } \\
\cline { 2 - 4 } & Group I & Group 2 & Group 3 \\
\hline Extracellular Nox from blood serum & $14.6 \pm 1.3$ & $8.45 \pm 0.7, P=0.01$ & $9.3 \pm 0.6, P=0.02$ \\
Nox from EM & $10.7 \pm 0.3$ & $4.3 \pm 0.06, P=0.04$ & $3.3 \pm 0.08, P=0.01$ \\
Nox from SCM & $8.6 \pm 0.2$ & $5.8 \pm 0.3, P=0.02$ & $6.4 \pm 0.5, P=0.02$ \\
Nox from SCN & $10.1 \pm 0.5$ & $7.1 \pm 0.2, P=002$ & $7.6 \pm 0.3, P=0.01$ \\
Nox from SCMI & $16.1 \pm 2.8$ & $11.7 \pm 2.0, P=0.01$ & $13.8 \pm 2.2, P=0.03$ \\
\hline
\end{tabular}

Notes: Data are expressed as mean \pm SD. Significance accepted at $P<0.05 ; \mathrm{n}=16$ in each group.

Abbreviations: ferriHB, ferrihemoglobin; MPA, prooxidative metalloproteins; EM, erythrocyte membrane; SCM, spleen cell membrane; SCN, spleen cell nuclei; SCMI, spleen cell mitochondria. 
Table 4 The changes of specific SOD and catalase activity in the erythrocyte and spleen cytosol in study groups

\begin{tabular}{lccc}
\hline MAA & \multicolumn{2}{c}{ Units of optical density/mg protein } & Group 3 \\
\cline { 2 - 4 } & Group I & Group 2 & $129.5 \pm 13.7, P=0.04$ \\
\hline $\begin{array}{l}\text { Fraction of Cu,Zn-SOD from the cytosol } \\
\text { of erythrocytes }\end{array}$ & $304.8 \pm 50.7$ & $78.6 \pm 6.9, P=0.04$ & $121.6 \pm 16.4, P=0.01$ \\
$\begin{array}{l}\text { Total fraction of Cu,Zn-SOD and Mn-COD } \\
\text { from the cytosol of spleen cells }\end{array}$ & $210.5 \pm 21.5$ & $65.4 \pm 8.7, P=0.01$ & $1505 \pm 140.6, P=0.01$ \\
$\begin{array}{l}\text { Fraction of catalase from the cytosol } \\
\text { of erythrocytes }\end{array}$ & $2100.0 \pm 201.7$ & $1182.3 \pm 123.9, P=0.04$ & $319.3 \pm 40.3, P=0.01$ \\
$\begin{array}{l}\text { Fraction of catalase from the cytosol } \\
\text { of spleen cells }\end{array}$ & $430.0 \pm 42.8$ & $248.9 \pm 20.6, P=0.03$ &
\end{tabular}

Notes: Data are expressed as mean \pm SD. Significance accepted at $P<0.05 ; n=16$ in each group.

Abbreviations: SOD, superoxide dismutase; MAA, antioxidative metalloproteins.

As for antioxidative metalloprotein, we can see that in STZ-induced diabetes the activity of the Cu,Zn-SOD fraction from the erythrocyte cytosol and the activity of the total fraction of $\mathrm{Cu}, \mathrm{Zn}-\mathrm{SOD}$ and Mn-SOD from the spleen cells were decreased in almost the same range (Table 4).

The catalase activity in the erythrocyte and spleen cytosols was also definitely decreased. The prophylactic administration of PEG (Group 3) resulted in increased activity of these key antioxidant enzymes and decreased $\mathrm{NADPH}$-dependent $\mathrm{O}_{2}^{-}$-producing activity of Noxes and $\mathrm{O}_{2}^{-}$-producing activity of suprol, indicating its antioxidant effect.

\section{Discussion}

To the authors' knowledge, this is the first study investigating the effects of this novel PEG preparation on the model of diabetes mellitus. The obtained results reveal that in STZinduced diabetes a decrease in stability of EM, SCM, SCN, and SCMI and enhancement of releasing of isoforms of Nox from heterogeneous phase (from membranes) to the homogeneous phase (in solution) took place, resulting in increased lipid peroxidation in biomembranes. ${ }^{25-27}$ This is confirmed by a significant decrease in the process of Nox release from EM and increased stability of the latter under the influence of drugs with antioxidant activity $(\mathrm{Cu}, \mathrm{Zn}-\mathrm{SOD}$, catalase, and ceruloplasmin, as well as a synthetic analog of the proline-rich polypeptide galarmin from neurosecretory granules of the hypothalamus). ${ }^{28}$

The increased level of eNox is possibly associated with the decreased erythrocyte stability. This phenomenon is observed in various pathological states, especially with malignant tumors. ${ }^{29,30}$ The mechanism of increasing the level of cyt c from SCM in STZ-induced diabetes can be connected with the decreased mitochondria stability.
In Group 3, the mechanism of PEG-induced normalization of Nox is not related to its antioxidant action (PEG does not possess SOD-mimetic or catalase-mimetic activity in vitro). It is more likely that the effect of PEG is associated with increase of the levels of antioxidant systems in vivo.

The uniqueness of PEG is that the combined preparation plays not only a positive antitumor ${ }^{17}$ and neuroprotective ${ }^{18}$ role, but also an antidiabetic role by regulating the level and activity of key anti- and prooxidative metalloproteins - the regulators of ROS metabolism.

Thus, the obtained results, as well as our previous results, ${ }^{31}$ indicate that $\mathrm{PEG}$ reveals a prophylactic (preventive) effect in experimental diabetes mellitus. This universality of the drug is potentially conditioned by its ability to modulate the general adaptive mechanisms operating on the molecular level at the initial stages of the pathological process. More studies are necessary to evaluate the potential short- and long-term side effects of PEG.

\section{Disclosure}

The authors report no conflicts of interest in this work.

\section{References}

1. Szkudelski T. The mechanism of alloxan and streptozotocin action in B cells of the rat pancreas. Physiol Res. 2001;50:537-546.

2. Bedoya FJ, Solano F, Lucas M. N-monomethyl-arginine and nicotinamide prevent streptozotocin-induced double strand DNA break formation in pancreatic rat islets. Experientia. 1996;52:344-347.

3. Nukatsuka K, Yoshimura Y, Nishida M, Kawada J. Importance of the concentration of ATP in rat pancreatic beta cells in the mechanism of streptozotocin-induced cytotoxicity. J Endocrinol. 1990;127: 161-165.

4. Kröncke KD, Fehsel K, Sommer A, Rodriguez ML, Kolb-Bachofen V. Nitric oxide generation during cellular metabolization of the diabetogenic N-methyl-N-nitroso-urea streptozotocin contributes to islet cell DNA damage. Biol Chem Hoppe Sayler. 1995;376: 179-185. 
5. Etoh T, Inoguchi T, Kakimoto $\mathrm{M}$, et al. Increased expression of NAD(P) H oxidase subunits, NOX 4 and p22phox in the kidney of streptozotocininduced diabetic rats and its reversibility by interventive insulin treatment. Diabetologia. 2003;46:1428-1437.

6. Luo ZF, Feng B, Mu J, et al. Effects of 4-phenylburitic acid on the process and development of diabetic nephropathy induced in rats by streptozotocin: regulation of endoplasmic reticulum stress-oxidative activation. Toxicol Appl Pharmacol. 2010;246(1-2):49-57.

7. Lopez-Lopez JC, Moral-Sanz J, Frazziano G, et al. Diabetes induces pulmonary artery endothelial dysfunction by NADPH oxidase induction. Am J Physiol Lung Cell Mol Physiol. 2008;295(5):L727-L732.

8. Mohamadin AM, Hammad LN, El-Bab MF, Gawad HS. Can nitric oxide-generating compounds improve the oxidative stress response in experimentally diabetic rats? Clin Exp Pharmacol Physiol. 2007;34(7): 586-593.

9. Miyamoto A, Takeshita M, Pan-Hou H, Fujimori H. Hepatic changes in adenine nucleotide levels and adenine 3-monophosphate formation enzyme in streptozotocin-induced diabetic mice. J Toxicol Sci. 2008; 33(2):209-217.

10. Xiang FL, Lu X, Strutt B, Hill DJ, Feng Q. NOX2 deficiency protects against streptozotocin-induced beta-cell destruction and development of diabetes in mice. Diabetes. 2010;59:2603-2611.

11. Peixoto EB, Pessoa BS, Biswas SK, Lopes de Faria JB. Antioxidant SOD mimetic prevents NADPH oxidase-induced oxidative stress and renal damage in the early stage experimental diabetes and hypertension. Am J Nephrol. 2009;29(4):309-318.

12. Sivakumar S, Subramanian SP. Pancreatic tissue protective nature of D-pinitol studied in streptozotocin-mediated oxidative stress in experimental diabetic rats. Eur J Pharmacol. 2009;622:65-70.

13. Bagri P, Ali M, Aeri V, Bhowmik M, Sultana S. Antidiabetic effect of Punica granatum flowers: effect of hyperlipidemia, pancreatic cells lipid peroxidation and antioxidant enzymes in experimental diabetes. Food Chem Toxicol. 2009;47:50-54.

14. Vignais PV.The superoxide-generating NADPH oxidase: structural aspects and activation mechanism. Cell Mol Life Sci. 2002;59:1428-1459.

15. Mkrtchyan LN. Embryonal antitumor modulator of Mkrtchyan, method of production and application. Patent of Russian Federation. 2004; No 2240810. Russian.

16. Mkrtchyan LN. In fight against cancer the prevention is essential. The New Arm Med J. 2009;3:90-95.

17. Mkrtchyan LN. On a new strategy of preventive oncology. Neurochem Res. 2010;35:868-874.

18. Yenkoyan KB. Neuroprotective role of proteoglycans of embryonic origin in the $\beta$-amyloid-induced neurodegeneration by influencing the insulin-like growth factor 1. Med Sci Edu. 2009;4:3-10. Russian.

19. Simonyan GM, Simonyan RM, Babayan MA, Simonyan MA, GaloyanAA. FAD and carbohydrate residues in the erythrocyte membrane cytochrome $\mathrm{b}_{558}$, it NADPH dependent superoxide-producing activity and the EPR spectral characteristics. Medl Sci Arm. 2003;43(1):30-34. Russian.
20. Simonyan GM,Simonyan RM, Simonyan MA. The reduction of hemoglobin by erythrocyte membranes cytochrome $b_{558}$ at various pathological states in vitro. On-line J Nat Sci. NAS RA. 2006;2:3-6. Russian.

21. Simonyan MA, Simonyan GM, Simonyan RM. Method of obtaining blood metalloproteins. Patent of Armenia. 1997; No 341, Yerevan. Russian.

22. Simonyan GM, Simonyan RM, Simonyan MA. Process for obtaining cytochrome b558 of erythrocyte membranes. Patent Armenia. 2001; No 908, Yerevan. 2001. Russian.

23. Simonyan GM, Simonyan RM, Simonyan MA. Process for obtaining cytochrome b558 from cellular components. Patent Armenia. 2008; No 2233 Yerevan. Russian.

24. Simonyan RM, Simonyan GM, Babayan MA, Simonyan MA, GaloyanAA. Translocation of cytochrome $\mathrm{b}_{558}$ from the membranes of intact red blood cells and irradiated by $\mathrm{X}$ rays of the blood during their incubation in vitro. Suppression of this process by the antioxidants. Med Sci Arm. 2003;43(3):26-31. Russian.

25. Soman S, Rauf AA, Indira M, Rajamanickam C. Antioxidant and antiglycative potential of ethyl acetate formation of Psidium guajava leaf extract in streptozotocin-induced diabetic rats. Plant Foods Hum Nutr. 2010;65(4):386-391.

26. Kamboj SS, Sandhir R. Protective effect of N-acethylcysteine supplementation on mitochondrial oxidative stress and mitochondrial enzymes in cerebral cortex of streptozotocin-induced diabetic rats. Mitochondrion. 2011;11(1):214-222.

27. Bozkurt O, Severcan M, Severcan F. Diabetes induces compositional, structural and functional alteration on rat skeletal soleus muscle revealed by FTIR spectroscopy: a comparative study with EDL muscle. Analyst. 2010;135(12):3110-3119.

28. Simonyan GM, Simonyan RM, Simonyan MA. Production of the serum cytochrome $b_{558}$ as a result of incubation of blood in vitro. Med Sci Arm. 2005;45(2):26-29. Russian.

29. Simonyan GM, Nersesian AK, Simonyan RM, Babayan MA, Simonyan MA, Galoyan AA. The antitumor and antistressor effects of hypothalamic proline rich polypeptide (PRP-1) at sarcoma-45: possible biochemical mechanisms. Neurochemistry. 2005;22(2):125-130. Russian.

30. Simonyan RM, Simonyan GM, Simonyan MA. The inhibition of superoxide-producing activity of the suprol by cytochrome $\mathrm{b}_{558}$ and its stimulation by $\mathrm{CCI}_{4}$ in vitro. Proc Nat Acad Sci RA. 2005;105(4): 384-389. Russian.

31. Vahedian V, Aghajanova EM. Experimental diabetes mellitus and its prevention by proteoglycans of embryonal genesis. The New Arm Med J. 2010;4(1):139-140.
Research and Reports in Biochemistry

\section{Publish your work in this journal}

Research and Reports in Biochemistry is an international, peer-reviewed, open access journal publishing original research, reports, reviews and commentaries on all areas of biochemistry. The manuscript management system is completely online and includes a very quick and fair
Dovepress

peer-review system. Visit http://www.dovepress.com/testimonials.php to read real quotes from published authors. 